\title{
PENERAPAN PROMOTIONAL MIX PADA BIRO PERJALANAN UMROH/ HAJI SHAFIRA TOUR AND TRAVEL SURABAYA MENURUT PERSPEKTIF ISLAM')
}

\author{
Kamilina Rhodiyah LD \\ Program Studi Ekonomi Islam-Fakultas Ekonomi dan Bisnis-Universitas Airlangga \\ Email: kammilinaLD@ymail.com \\ Fatin Fadhillah Hasib \\ Departemen Ekonomi Syariah-Fakultas Ekonomi dan Bisnis-Universitas Airlangga \\ Email: fatin.fadhilah@gmail.com
}

\begin{abstract}
:
An Increasing number of jama'ah Umrah/Haj in Indonesia every year the show will be the enthusiasm of the congregation to worship in the Holy Land that is not uncommon travel agency action that defraud prospective pilgrims by providing false promotions. This study aims to determine how the promotional mix is right according to Islamic perspective. This study used a qualitative approach with case study method is the shafira Tour and Travel in Surabaya. Data collection techniques is a questionnaires, an interviews and a documentation.Based on the research results, the implementation of sixth promotional mix done by Shafira Tour and Travel compatible with the promotion of the Islamic perspective that is honest, Amanah, does not promote illicit goods and carry out advice based on the results of other studies, congregation only knew four of six promotional mix which is done is through ads, personal selling, sales promotion and WOM.
\end{abstract}

Keywords: Tour and Travel, Promotion, Application of Promotional Mix, Umrah/ Hajj.

\section{PENDAHULUAN}

\section{Latar Belakang}

Islam mengajarkan pada umatnya agar saling mengenal, tidak saja terhadap orang-orang semasa hidup, melainkan juga terhadap orang-orang yang hidup di masa jauh sebelumnya. Kitab suci AlQur'an memperkenalkan nama-nama para rasul, nabi dan orang-orang terpilih lainnya. Selain itu, sebagai salah satu rangkaian ibadah haji adalah wukuf di arafah. Haji pada hakekatnya merupakan sarana dan media bagi umat Islam untuk menghidupkan ka'bah dan tanah suci setiap tahun karena setiap tahun sebagian kaum muslimin dari seluruh dunia datang menunaikan ibadah haji(Suprayogo, 2008).
Setiap tahunnya jama'ah haji semakin bertambah, sepanjang sejarah pelaksanaan Ibadah haji selalu mendapatkan perhatian khusus. Seiring bertambahnya pendaftar haji mengakibatkan kuota untuk menunaikan ibadah haji menjadi terbatas dan apabila calon jamaah haji ingin segera berangkat menuju ke Tanah Suci maka alternatif lain untuk menunaikan ibadah di tanah suci adalah Ibadah Umroh. Umroh adalah berkunjung ke Baitullah untuk melakukan Thawaf, Sa'i, dan bercukur demi mengharap ridha Allah SWT. Ibadah umroh dari tahun ke tahun juga jama'ah umroh juga bertambah. Banyak komponen dalam penyelenggaran ibadah haji, komponen itu mulai dari pendaftaran, transportasi, akomodasi,

1) Jurnal ini merupakan bagian dari Skripsi yang ditulis oleh (Kamilina Rhodiyah LD:041114149), yang diuji pada 29 Oktober 2015 
Rhodiyah LD, et al/Jurnal Ekonomi Syariah Teori dan Terapan Vol. 3 No. 1 Januari 2016: 1-15; PENERAPAN PROMOTIONAL MIX PADA BIRO PERJALANAN UMROH/ HAJI SHAFIRA TOUR AND TRAVEL SURABAYA MENURUT PERSPEKTIF ISLAM.

keamanan, catering dan kesehatan(Nizam dan Hasan, 2000:45).

Tabel 1. Laporan Penyelenggaran Perjalanan Ibadah Umroh tahun 2015

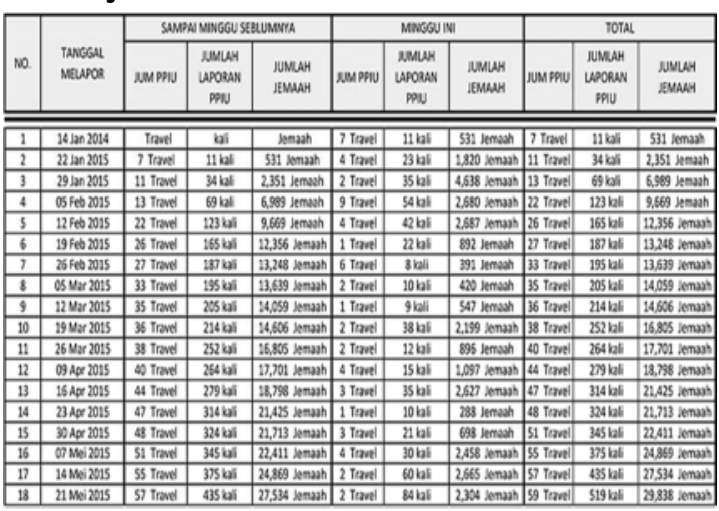

Sumber: KementerianAgama Republik Indonesia

(http://www.kantorurusanhaji.com)

Pada tabel 1. ditunjukkan bahwa setiap minggunya jumlah jama'ah umroh pada 14 Januari 2015- 21 Mei 2015 terus meningkat hal ini mengakibatkan bisnis travel agent mulai menjamur. Peningkatan ekonomi masyarakat Indonesia juga mendorong terus berkembangnya bisnis ini tidak tertinggal pula bisnis tour travel yang hanya menawarkan jasa pelayanan perjalanan ibadah ke tanah suci, baik umroh maupun haji.

Perkembangannya sangat terlihat yaitu dengan adanya pasar terbuka yang sangat luas terlebih lagi dikarenakan penduduk Indonesia mayoritasnya adalah kaum muslim sehingga mengakibatkan permintaan keberangkatan umroh sebagai pengganti ibadah Haji dari bulan ke bulan yang semakin meningkat membuat bisnis travel semakin menjamur. Selain itu, peningkatan ekonomi masyarakat Indonesia juga mendorong terus berkembangnya bisnis ini. Bisnis jasa

Tour and Travel akhirnya menjadi salah satu peluang usaha yang cukup menarik untuk dilakukan oleh pelaku bisnis. Perkembangan jasa travel yang semakin pesat mengakibatkan tingginya tingkat persaingan. Oleh karena itu, perusahaan travel harus berorientasi pada kepuasan pelanggan dengan meningkatkan nilai bagi para pelanggan tanpa mengurangi kualitas pelayanan jasa tersebut. Hal ini digambarkan dengan slogan umum dalam bisnis yaitu "Customer is partner" (Berten, 2000:227).

Untuk menghadapi persaingan pasar yang ketat, membedakan penerapan strategi pemasaran merupakan suatu keharusan. Keunggulan dasar yang diperoleh perusahaan ketika mampu menerapkan strategi pemasaran yaitu dapat meningkatkan kinerja pemasaran dan pembelanjaan organisasi. Kegiatan pemasaran dalam bisnis tour and travel ini sangatlah berperan penting dalam kegiatan bisnis agar dapat berjalan sesuai dengan rencana. Di dalam kegiatan pemasaran terdapat sarana bauran pemasaran (Marketing Mix) yang melambangkan aktivitasaktivitas pemasaran yang telah dikelompokan mejadi empat jenis sehingga pada akhirnya akan membantu pemasar membuat keputusan pemasaran untuk mempengaruhi saluran perdagangan mereka dan konsumen akhir mereka. Komponen Marketing Mix tersebut adalah Product (Produk), Price (Harga), Promotion (Promosi), Product 
Rhodiyah LD, et al/Jurnal Ekonomi Syariah Teori dan Terapan Vol. 3 No. 1 Januari 2016: 1-15; PENERAPAN PROMOTIONAL MIX PADA BIRO PERJALANAN UMROH/ HAJI SHAFIRA TOUR AND TRAVEL SURABAYA MENURUT PERSPEKTIF ISLAM.

(Produk), dan People (Orang). Product merupakan barang atau jasa yang ditawarkan perusahaan kepada konsumen. Di dalam product terkandung ragam produk, kualotas, desain, fitur, nama merek, kemasan, ukuran, layanan, jaminan, dan pengembalian. Price merupakan nilai yang akan di bayarkan oleh konsumen atau nilai yang mencerminkan biaya yang digunakan untuk menghasilkan suatu barang atau jasa. Promotion merupakan aktivitas mengkomunikasikan atau menginformasikan kepada konsumen mengenai produk yang ditawarkan. Place merupakan akses dimana konsumen dapat memperoleh produk yang ditawarkan. Sedangkan People merupakan sumber daya manusia yang perlu diperhatikan dan dikembangkan agar dapat memberikan sumbangsih bagi perusahaan, dalam perusahaan jasa orang/karyawan merupakan bagian kerja dari sebuah perusahaan yang dapat memberikan pelayanan bagi konsumen (Kotler, 2005:116)

Biro perjalanan umroh/haji SHAFIRA Tour and Travel Surabaya merupakan satu dari beberapa biro perjalanan umroh/haji yang ada di Surabaya sebagai bisnis yang bergerak dalam bidang travel dengan persaingan yang cukup ketat dengan biro perjalanan umroh/haji lain, membuat biro perjalanan umroh/haji SHAFIRA Tour and Travel Surabaya dituntut untuk memiliki kebijakan tentang pemasaran secara efektif dan efisien dalam mepromosikan produknya. Selain itu Biro perjalanan umroh/Haji SHAFIRA Tour and Travel ini dipilih berdasarkan prestasi-prestasi yang sudah didapatkan di antaranya penghargaan dari Hotel Anwar Al Madinah Movenpick untuk kerjasama produktif selama Umrah dan Haji pada tahun 2014 dan pada tahun 2015 SHAFIRA Tour and Travel juga mendapatkan penghargaan untuk Best Performance International Agent yang diberikan oleh Garuda Indonesia kepada SHAFIRA (anonim, 2015).

Berdasarkan latar belakang diatas dapat disimpulkan bahwa perkembangan bisnis travel yang setiap tahunnya selalu meningkat maka dapat menyebabkan persaingan yang sangat ketat pada peningkatan hasil penjualan dalam bidang biro jasa perjalanan umroh/haji sehingga promotional mix di SHAFIRA Tour and Traveldan untuk memperkuat kegiatan promotional mix yang dilakukan telah sesuai dengan syariat islam, maka penulis tertarik mengangkat permasalahan tersebut dengan judul"Penerapan Promotional Mix PadaBiro Perjalanan Umroh/ Haji SHAFIRA Tourand Travel Surabaya Menurut Perspektif Islam."

\section{Rumusan Masalah}

Berdasarkan latar belakang yang telah diuraikan diatas maka dapat dirumuskan bahwa pokok-pokok permasalahan yang dibahas adalah sebagai berikut: 
Rhodiyah LD, et al/Jurnal Ekonomi Syariah Teori dan Terapan Vol. 3 No. 1 Januari 2016: 1-15; PENERAPAN PROMOTIONAL MIX PADA BIRO PERJALANAN UMROH/ HAJI SHAFIRA TOUR AND TRAVEL SURABAYA MENURUT PERSPEKTIF ISLAM.

1. Bagaimanakah penerapan bauran promosi (Promotional Mix) yang dilakukan oleh pihak SHAFIRATour and Travel terhadap produk jasanya?

2. Apakah promosiyang dilakukan oleh pihak SHAFIRA Tour and Travel pada produk jasanya sesuai dengan perspektif Islam?

\section{Tujuan Penelitian}

Tujuan penelitian yang hendak dicapai dengan melakukan penelitian ini antara lain :

1. Untuk mengetahui bauran promosi (Promotional Mix) yang dilakukan oleh SHAFIRA Tour and Travel terhadap produk jasanya;

2. Untuk mengetahui promosi yang telah dilakukan terhadap produk jasa diSHAFIRA Tour and Travel sudah sesuai dengan perspektif Islam.

\section{LANDASAN PUSTAKA}

\section{Muamalah}

Menurut Haroen (2007:2), kata muamalat (المعا ملا ت)yang kata tunggalnya berakar pada kata عَامَ jecara arti kata mengandung arti "saling berbuat" atau berbuat secara timbal balik. Kata ini, menggambarkan suatu aktivitas yang dilakukan oleh seseorang dengan seseorang atau beberapa orang dakam memenuhi kebutuhan masing-masing. Ruang lingkup muamalah terdiri dari dua yaitu:

a.Muamalah Madiyah, pada muamalah madiyah membahas tentang jual beli, sewa menyewa, gadai, jaminan, dan tanggungan, hiwalah, syirkah, dan 'ariyah (Ghazaly,dkk 2010:2). Sedangkan;

b. Muamalah adabiyahmembahas tentang ijab, kabul, saling meridai, hak dan kewajiban, kejujuran pedagang, penipuan, pemalsuan, dan segala sesuatu yang bersumber, dari indra manusia yang ada kaitannya dengan peredaran harta dalam bermasyarakat (Ghazaly,dkk 2010:2)

\section{Pemasaran}

Pengertian pemasaran menurut Kotler (2005:10) adalah suatu proses sosial dan manajerial yang mana dengan proses itu individu dan kelompok mendapatkan apa yang mereka butuhkan dan inginkan daengan menciptkan, menawarkan dan secara bebas mempertukanrkan produk dan jasa yang bernilai dengan pihak lain. Pemasaran juga dapat di artikan sebagai upaya untuk menciptakan dan menjual produk kepada berbagai pihak dengan maksud tertentu (Kasmir dan Jakfar, 2004:74).

\section{Marketing Mix}

Marketing Mix (bauran pemasaran) merupakan kegiatan pemasaran yang dilakukan secara terpadu. Artinya kegiatan ini dilakukan secara bersamaan diantara elemen-elemen yang ada di dalam marketing mix itu sendiri.Setiap elemen tidak dapat berjalan sendiri-sendiri tanpa dukungan dari elemen yang lain. 
Rhodiyah LD, et al/Jurnal Ekonomi Syariah Teori dan Terapan Vol. 3 No. 1 Januari 2016: 1-15; PENERAPAN PROMOTIONAL MIX PADA BIRO PERJALANAN UMROH/ HAJI SHAFIRA TOUR AND TRAVEL SURABAYA MENURUT PERSPEKTIF ISLAM.

Elemen-elemen yang ada dalam marketing mix menurut Kasmir dan Jakfar (2012: 51) adalah Product (produk), Price (Harga), Place (Tempat), dan Promotion (promosi) atau yang biasa disebut 4P.

\section{Pemasaran Syariah (Syariah Marketing)}

Kartajaya dan Sula (2006:62) menjelaskan bahwa:

Syariah marketing adalah sebuah disiplin bisnis strategis yang mengarahkan proses penciptaan, penawaran, dan perubahan value dari suatu inisiator kepada stakeholders-nya, yang dalam keseluruhan prosesnya sesuai dengan akad dan prinsip-prinsip muamalah (bisnis) dalam Islam.

Dari definisi di atas dapat diketahui bahwa:

Syariah marketing, merupakan seluruh proses mulai dari proses penciptaan, proses penawaran, maupun proses perubahan nilai (value) tidak boleh ada hal-hal yang bertentangan dengan akad dan prinsip-prinsip muamalah yang islami. Selama hal tersebut dapat dijamin, dan penyimpangan prinsipprinsip muamalah yang Islami tidak terjadi dalam suatu transaksi atau dalam proses suatu bisnis (Kartajaya dan Sula, 2006:63).

Prinsip-prinsip pemasaran Islam menggabungkan konsep maksimalisasi nilai dengan prinsip 'keadilan' untuk kesejahteraan yang lebih luas di masyarakat. Prinsip-prinsip ini menawarkan cara untuk menciptakan nilai dan meninggikan taraf hidup masyarakat secara umum melalui kegiatan komersial. Kebutuhan konsumen telah berfokus pada perubahan yang sangat cepat bagi kegiatan pemasaran.

\section{Marketing Mix dalam perspektif Islam}

Kebanyakan agama meresepkan atau melarang perilaku tertentu, termasuk perilaku konsumsi. Sebagai contoh, Essoo dan Dibb (2004:706) menemukan dalam penelitiannyai:

"Nilai praktis dari penelitian ini adalah bahwa strategi pemasaran dapat menemukannyaberguna dengan tujuan untuk melihat afiliasi keagamaan dan religiusitas sebagai prediktor perilaku konsumen Pemahaman yang disempurnakan perbedaan agama dalam konsumsi bisa bergunaditerapkan dalam pengembangan strategi dan taktik pemasaran.Pada tingkat strategis,mungkin ada nilai dalam menggunakan agama sebagai dasar segmentasi.Taktik pemasaran mungkinkemudian dirancang yang mencerminkan dan lebih cocok dengan karakteristik konsumen perilaku dalam kelompok agama yang berbeda. "

Hasan dan Latiff (2008:30), membuat upaya untuk menganalisis pemasaran yaitu dengan lima $P$ (5P) dari Marketing Mix yaitu antara lain : Produk (Product), Harga (Price), Promosi (Promotion), Tempat (Place), dan Orang (Peoples) .

\section{Bauran Promosi}

Menurut Basu Swastha (1998:228), promotional mix adalah kombinasi strategi yang paling baik dari variabel-variabel Periklanan, Personal Selling dan alat Promosi lainnya, yang semuanya direncanakan untuk mencapai tujuan program penjualan. 
Rhodiyah LD, et al/Jurnal Ekonomi Syariah Teori dan Terapan Vol. 3 No. 1 Januari 2016: 1-15; PENERAPAN PROMOTIONAL MIX PADA BIRO PERJALANAN UMROH/ HAJI SHAFIRA TOUR AND TRAVEL SURABAYA MENURUT PERSPEKTIF ISLAM.

Bauran promosi tersebut merupakan alat komunikasi pemasaran produk agar sampai pada pelanggan. Promosi, bauran promosi ataupun komunikasi pemasaran terintegrasi menjadi suatu manajemen integrated marketing communication (IMC), sebagaimana gambar 1. berikut ini:

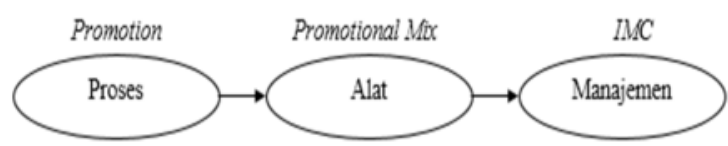

Sumber: Richard J. Semenik. 2002. Promotion and Integrated Marketing Communication. Ohio. South Western Thompson learning

\section{Gambar 1.}

\section{Skema Komunikasi Pemasaran Terpadu}

Gambar 1 disampaikan oleh Semenik (2002: 9) bahwa promosi merupakan suatu proses yang membutuhkan alat yakni penggunaan bauran promosi, dari dua hal tersebut akan digabungkan pada suatu manajemen sehingga menjadi suatu integrated marketing communication (IMC). IMC merupakan konsep sederhana yang mengarahakan semua bentuk komunikasi menuju pada satu solusi. Implementasi dari manajemen IMC yang baik dapat menghasilkan suatu integrasi dalam pesan dan tujuan perusahaan.

\section{Promosi menurut Perspektif Islam}

Menurut Anwar and Saeed (1996), "Alat promosi, terutama iklan, memainkan peran penting dalam orientasi nilai, karena mereka membentuk dan mencerminkan nilai-nilai masyarakat. Iklan dan langkah-langkah promosi lainnya, diterapkan di masyarakat muslim". Oleh karena itu, perhatian khusus harus dibayar untuk merancang promosi yang akan membantu dalam memproyeksikan nilainilai Islam, membangun karakter pelanggan, dan menyebarkan kebenaran dalam masyarakat.

\section{METODE PENELITIAN}

\section{Pendekatan Penelitian}

Penelitian ini menggunakan pendekatan kualitatif deskriptif. Pendekatan kualitatif menurut Moleong (2010:6) merupakan penelitian yang bermaksud memahami fenomena tentang apa yang dialami oleh subyek penelitian misalnya perilaku, persepsi, motivasi, tindakan, dan lain-lain, secara holistik, dan dengan cara deskripsi dalam bentuk kata-kata dan bahasa, pada suatu konteks khusus yang alamiah dan dengan memanfaatkan berbagai metode ilmiah.

Penelitian ini juga menggunakan metode studi lapangan (studi kasus) yang secara umum merupakan strategi yang lebih cocok bila pokok pertanyaan suatu penelitian berkenaan dengan how, why, bila peneliti hanya memiliki sedikit peluang untuk mengontrol peristiwa-peristiwa yang akan diselidiki, dan apabila peneliti terlibat langsung dalam penelitian, dan bilamana fokus penelitian terletak pada fenomena kontemporer (masa kini) di dalam konteks kehidupan nyata, serta proposisi di dalamnya (Yin, 2003:1).

\section{Sumber Data}

Sumber data dalam penelitian ini adalah : 
Rhodiyah LD, et al/Jurnal Ekonomi Syariah Teori dan Terapan Vol. 3 No. 1 Januari 2016: 1-15; PENERAPAN PROMOTIONAL MIX PADA BIRO PERJALANAN UMROH/ HAJI SHAFIRA TOUR AND TRAVEL SURABAYA MENURUT PERSPEKTIF ISLAM.

1. Informan

Dalam

penelitian

ini

menggunakanpurposive sampling,

karena diharapkan dengan memilih orang yang paling tahu maka peneliti akan mendapatkan hasil penelitian yang maksimal.Sehinggan informan utama yang dijadikan sumber data dalam penelitian ini adalah manajermarketing dan staff penjualan (customer service) SHAFIRA Tour and Travel Surabaya yang diharapkan memahami secara menyeluruh informasi yang dibutuhkan.

2. Data Penunjang

Data penunjang berupa data sekunder yang berasal dari catatan, laporan, informasi umum perusahaan bisa digunakan sebagai sumber informasi dalam penelitian.

\section{Teknik Pengumpulan Data}

Prosedur pengumpulan data pada penelitian ini denganpenelitian lapangan. Penelitian lapangan bertujuan untuk memperoleh data secara akurat sebagai dasar dalam proses analisis selajutnya. Teknik yang digunakan dalam penelitian lapangan :

1. Wawancara

Dengan melakukan wawancara mendalam, peneliti berusaha untuk mendapatkan data yang dibutuhkan yang berupa informasi tentang penerapan promotional mix pada SHAFIRA Tour and Travel Surabaya

2. Teknik Dokumentasi
Dalam penelitian ini teknik dokumentasi dilakukan untuk memperoleh data berupa gambar, laporan, catatan yang mendukung penelitian.

\section{Teknik Analisis}

Yin (2002:133) membagi tiga teknik analalisis untuk studi kasus, yaitu penjodohan pola, pembuatan penjelasan, dan analisis deret waktu. Pada penelitian ini hanya digunakan dua teknik analisis yaitu

1. Teknik analisis penjodohan pola dengan cara membandingkan promotional mix yang dilakukan oleh SHAFIRA dan promosi dalam perspektif Islam berdasarkan segi pandang pihak internal dan eksternal.

2. Teknik pembuatan penjelasan dilakukan dengan cara membuat penjelasan atau analisis tentang serangkaian peristiwa aktual studi kasus mengenai penerapan promotional mix di SHAFIRA dan promosi dalam perspektif Islam.

3. Teknik analisis deret waktu tidak digunakan pada penelitian ini dikarenakan penelitian ini tidak dilakukan dalam waktu berjangka atau historis.

\section{Teknik Keabsahan Data}

Keabsahan data dapat dilakukan dengan beberapa cara untuk memperoleh keabsahan data salah satunya dengan menggunakan 
Rhodiyah LD, et al/Jurnal Ekonomi Syariah Teori dan Terapan Vol. 3 No. 1 Januari 2016: 1-15; PENERAPAN PROMOTIONAL MIX PADA BIRO PERJALANAN UMROH/ HAJI SHAFIRA TOUR AND TRAVEL SURABAYA MENURUT PERSPEKTIF ISLAM.

triangulasi. Penelitian ini menggunakan triangulasi untuk mengecek data yang diperoleh dari informan yang telah diwawancarai yang terdiri dari pihak internal (dalam perusahaan) dan pihak eksternal perusahaan (luar perusahaan/konsumen). Proses validitas data pada penelitian ini menggunakan triangulasi sumber. Triangulasi sumber pada penelitian menurut Sugiyono (2010: 330) triangulasi sumber berarti untuk mendapatkan data dari sumber yang berbeda-beda dengan teknik yang sama. Hal ini dapat digambarkan sebagai berikut :

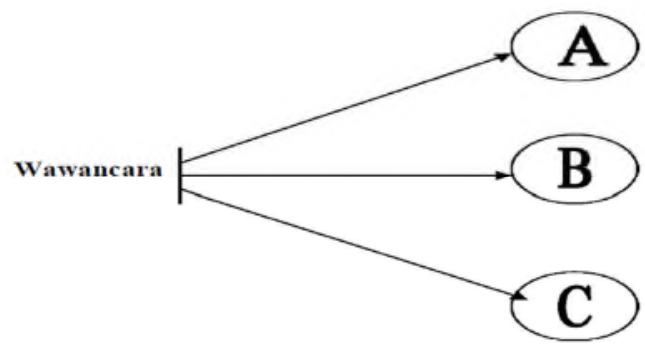

Sumber: Sugiyono. 2006 . Metode Penelitian Bisnis. Bandung: Alfabeta

\section{Gambar 2.}

Triangulasi "sumber" pengumpulan data Mathinson dalam Sugiyono (2010: 332) mengemukakan bahwa "the value of triangulation lies in providing evidence, whether convergent in consistent, or contracdictory" maksudnya nilai dari teknik pengumpulan data dengan triangulasi adalah untuk mengetahui data yang diperoleh convergent (meluas), tidak konsisten atau kontradiksi. Oleh karena itu, dengan menggunakan teknik triangulasi dalam pengumpulan data, maka data yang diperoleh akan lebih konsisten, tuntas dan pasti. Selain itu, dengan triangulasi akan lebih meningkatkan kekuatan data, apabila dibandingkan dengan satu pendekatan.

\section{HASIL PENELITIAN DAN PEMBAHASAN}

Pembahasan

Penerapan Promotional Mix pada Biro Perjalanan Umroh/ Haji di SHAFIRA Tour and Travel Surabaya Menurut Perspektif Islam

Menurut Basu Swastha (1998:228), promotional mix adalah kombinasi strategi yang paling baik dari variabel-variabel Periklanan, Personal Selling dan alat Promosi lainnya, yang semuanya direncanakan untuk mencapai tujuan program penjualan.

Bauran promosi juga merupakan cerminan perilaku Rasulullah SAW yang terdiri dari iklan, promosi penjualan, acara dan pengalaman, hubungan masyarakat dan publisitas, pemasaran langsung, pemasaran dari mulut ke mulut, serta penjualan tatap muka. Untuk menyempurnakan aktivitas promosipromosi yang dilakukan diharapkan ditanamkan kriteria-kriteria berpromosi menurut perspektif Islam yaitu Kejujuran, Amanah, Tidak mempromosikan barang haram, dan Nasehat (pelengkap Kejujuran dan Amanah).

Promotional Mix Perspektif Islam dengan kriteria Kejujuran

Promotional Mix yang dilakukan oleh SHAFIRA seperti Iklan, Pemasaran Langsung, Penjualan Pribadi, Acara dan Pengalaman, Publisitas dan Hubungan 
Rhodiyah LD, et al/Jurnal Ekonomi Syariah Teori dan Terapan Vol. 3 No. 1 Januari 2016: 1-15; PENERAPAN PROMOTIONAL MIX PADA BIRO PERJALANAN UMROH/ HAJI SHAFIRA TOUR AND TRAVEL SURABAYA MENURUT PERSPEKTIF ISLAM.

Masyarakat, Promosi Penjualan, telah disampaikan kepada calon jamaah dengan didasari kejujuran dan untuk Pemasaran dari mulut ke mulut hal ini dilakukan oleh para jamaah yang puas dengan pelayanan dari SHAFIRA karena mereka telah membuktikan sendiri dengan beribadah bersama SHAFIRA Tour and Travel.

Tabel 2. Jujur menurut pihak Travel dan Jamaah

\begin{tabular}{|c|c|}
\hline SHAFIRA & Jamaah \\
\hline $\begin{array}{l}\text { SHAFIRA } \\
\text { mengutamakan kejujuran dalam } \\
\text { berpromosi seperti: } \\
\text { 1. Menjelaskan tarif-tarif } \\
\text { berdasarkan paket-paket yang } \\
\text { tersedia; } \\
\text { 2. Menjelaskan adanya biaya } \\
\text { tambahan airport handling } \\
\text { diluar biaya utama; } \\
\text { 3. Menjelaskan tentang fasilitas- } \\
\text { fasilitas yang terdapat dalam } \\
\text { paket-paket yang tersedia. }\end{array}$ & $\begin{array}{l}\text { 1. Memberikan semua } \\
\text { informasi baik mengenai } \\
\text { harga, fasilitas, dan } \\
\text { transportasi yang digunakan. } \\
\text { 2. Sesuai dengan brosur/ } \\
\text { pamflet yang diberikan. }\end{array}$ \\
\hline Jmber: diolah & ISURि \\
\hline
\end{tabular}

Promotional Mix Perspektif Islam dengan kriteria Amanah

Promotional Mix yang dilakukan oleh SHAFIRA seperti Iklan, Pemasaran Langsung, Penjualan Pribadi, Acara dan Pengalaman, Publisitas dan Hubungan Masyarakat, Promosi Penjualan, juga diutamakan sifat Amanah yaitu dapat dipercaya seperti Iklan dan realita di lapangan sesuai dengan apa yang dibicarakan pada saat Iklan begitu pula dengan sarana promosi lainnya yang dilakukan di SHAFIRA. Akan tetapi untuk bauran promosi seperti word of mouth ini amanah akan terlihat ketika orang yang diberikan informasi oleh jamaah yang sudah pernah merasakan beribadah di SHAFIRA merasakannya secara langsung.
Hal ini ditunjukkan pada Tabel 3. Amanah menurut pihak Travel dan Jamaah dibawah ini:

Tabel 3.

Amanah menurut pihak Travel dan Jamaah

\begin{tabular}{|l|lr|}
\hline \multicolumn{1}{|c|}{ SHAFIRA } & \multicolumn{1}{|c|}{ Jamaah } \\
\hline 1. Memberikan segala keperluan & 1. Memberikan regala \\
untuk beribadah umroh/ haji & $\begin{array}{l}\text { keperluan untuk beribadah } \\
\text { umroh/haji dengan kualitas }\end{array}$ \\
seperti koper, hijab, dll; & $\begin{array}{l}\text { yang bagus; } \\
\text { 2. Memberikan fasilitas-fasilitas } \\
\text { yang sesuai dengan paket yang } \\
\text { dipilih oleh jamaah; }\end{array}$ & $\begin{array}{l}\text { 2. Memberikan fasilitas- } \\
\text { fasilitas yang sesuai dengan }\end{array}$ \\
3. Apabila ada komplain tentang & paket yang dipilih. \\
umroh/ haji seperti halnnya & \\
kerusakan pada koper maka & \\
SHAFIRA memberikan retur & \\
secara gratis. & \\
\hline
\end{tabular}

Sumber: diolah berdasarkan hasil penelitian

Promotional Mix Perspektif Islam dengan kriteria Larangan Mempromosikan barang Haram

Promotional Mix yang dilakukan oleh SHAFIRA seperti Iklan, Pemasaran Langsung, Penjualan Pribadi, Acara dan Pengalaman, Publisitas dan Hubungan Masyarakat, dan Word of Mouth tidak terdapat unsur mempromosikan barang haram seperti haram zatnya, haram selain zatnya, dan tidak sahnya akad.

Hal ini ditunjukkan pada Tabel 4. Larangan mempromosikan barang menurut Travel dan Jamaah dibawah ini:

Tabel 4.

Larangan mempromosikan barang haram menurut pihak Travel dan Jamaah

\begin{tabular}{|c|c|}
\hline SHAFIRA & Jamaah \\
\hline $\begin{array}{l}\text { 1. Pada zat produk yang dijual oleh } \\
\text { SHAFIRA halal dikarenakan tidak } \\
\text { mengandung babi, khamr, darah, } \\
\text { dan bangkai. }\end{array}$ & $\begin{array}{l}\text { 1. Pada zat produk yang dijual yaitu } \\
\text { berupa suatu jasa atau manfast } \\
\text { yang diberikan oleh pihak travel } \\
\text { dengan suatu kapemilikan aset } \\
\text { tetap yang dimiliki nya. }\end{array}$ \\
\hline $\begin{array}{l}\text { 3. Pada Tidak sahnya akad, pihak } \\
\text { SHAFIRA tidak perah } \\
\text { memberikan iming-iming hadiah } \\
\text { apabila jamaah mendaftar, selain } \\
\text { itu pihak SHAFIRA juga tidak } \\
\text { pernah memberikan syarat atau } \\
\text { ketentuan khusus apabila ingin } \\
\text { beribadah di travel agentnya. }\end{array}$ & $\begin{array}{l}\text { 2. Pada kriteria haram selain zatnya } \\
\text { tidak terdapat hal yang } \\
\text { mengindikasikan adanya unsur } \\
\text { Maghrib seperti keberadaan dan } \\
\text { wujud jasa yang ditransaksikan } \\
\text { tidak jelas (salah satu tidak } \\
\text { mengetahui), ataupun hal seperti } \\
\text { jasa yang ditransaksikan tidak jelas } \\
\text { apakah bisa diserahkan atau di } \\
\text { manfaatkan, pada SHAFIRA juga } \\
\text { tidak terdapat indikasi suatu } \\
\text { ketidakjelasan harga, kualitas, } \\
\text { kuantitas dari obyek transaksinya. }\end{array}$ \\
\hline & $\begin{array}{l}\text { 3. Pada tidak sahnya akad, SHAFIRA } \\
\text { tidak pernah memberikan suatu } \\
\text { iming-iming hadiah kepada para } \\
\text { calon jamaah/ jamaahnya karena } \\
\text { pihak SHAFIRA benar-benar } \\
\text { hanva melakukan peniualan saia. }\end{array}$ \\
\hline
\end{tabular}


Rhodiyah LD, et al/Jurnal Ekonomi Syariah Teori dan Terapan Vol. 3 No. 1 Januari 2016: 1-15; PENERAPAN PROMOTIONAL MIX PADA BIRO PERJALANAN UMROH/ HAJI SHAFIRA TOUR AND TRAVEL SURABAYA MENURUT PERSPEKTIF ISLAM.

Sumber: diolah berdasarkan hasil penelitian

Pada penelitian sebelumnya yang

Sumber: diolah berdasarkan hasil penelitian

\section{Promotional Mix Perspektif Islam dengan kriteria Nasehat}

SHAFIRA dalam melengkapi promotional mix dengan Jujur dan Amanah mereka juga memberikan sebuah Nasihat/ Saran pada calon jamaah agar sebelum mengikuti umroh/ haji pada suatu travel diharapkan agar mengecek apakah travel tersebut sudah memiliki izin. Akan tetapi di sisi Jamaah memiliki jawaban yang berbeda yaitu diharapkan untuk pihak SHAFIRA dalam hal melengkapi Jujur dan Amanah agar memperhatikan kebutuhan para jamaah terutama makanan yang sesuai dengan lidah orang Indonesia selain itu, diharapkan SHAFIRA juga lebih sering membagikan brosur/ pamflet agar lebih banyak masyarakat yang mengetahui sarana promosi mereka.

Hal ini ditunjukkan pada Tabel 5. Nasehat menurut pihak Travel dan Jamaah dibawah ini:

Tabel 5.Nasehat menurut pihak Travel dan Jamaah

\begin{tabular}{|c|c|}
\hline SHAFIRA & Jamaah \\
\hline $\begin{array}{l}\text { 1. SHAFIRA dalam melengkapi } \\
\text { Jujur dan Amanah memberikan } \\
\text { sebuah Nasihat/Saran pada calon } \\
\text { jamaah agar sebelum mengikuti } \\
\text { umroh/ haji pada suatu travel } \\
\text { diharapkan agar mengecek } \\
\text { apakah travel tersebut sudah } \\
\text { memiliki izin. }\end{array}$ & $\begin{array}{l}\text { 1. Menurut Jamash, diharapkan } \\
\text { untuk pihak SHAFIRA dalam } \\
\text { hal melengkapi Jujur dan } \\
\text { Amanah agar memperhatikan } \\
\text { kebutuhan para jamaah } \\
\text { terutama makanan yang sesuai } \\
\text { dengan lidah orang Indonesia }\end{array}$ \\
\hline
\end{tabular}

dilakukan oleh Pratiwi (2013) didapatkan kesimpulan etika bisnis terdiri dari shiddiq, istiqamah, fathanah, amanah, dan tabligh ini diuraikan sebagai berikut:

1. Etika bisnis Islam (Shiddia) dalam komunikasi pemasaran diterapkan oleh SHAFIRA Tour and Travel dengan cara menyampaikan secara terbuka, tidak menutup-nutupi, tidak menjebak, tidak melebih-lebihkan serta sesuai dengan apa yang telah diprogramkan dalam umroh maupun haji.

2. Etika bisnis Islam (Istiqamah) dalam komunikasi pemasaran diterapkan oleh SHAFIRA Tour and Travel dengan cara menjadwalkan untuk semua iklan, baik iklan di TV maupun di radio, serta mengagendakan ketika terdapat event atau ekspo umroh atau haji. SHAFIRA Tour and Travel juga mengulang kembali penyampaian informasi baik kepada jamaah yang telah menjadi pelanggan tetap maupun kepada jamaah baru.

3. Etika bisnis Islam (Fathanah) dalam komunikasi pemasaran diterapkan oleh SHAFIRA Tour and Travel dengan cara mengemas iklan dengan kemasan yang menarik sehingga menarik minat jamaah, tanpa mengabaikan nilai-nilai kejujuran. 
Rhodiyah LD, et al/Jurnal Ekonomi Syariah Teori dan Terapan Vol. 3 No. 1 Januari 2016: 1-15; PENERAPAN PROMOTIONAL MIX PADA BIRO PERJALANAN UMROH/ HAJI SHAFIRA TOUR AND TRAVEL SURABAYA MENURUT PERSPEKTIF ISLAM.

Selain itu, SHAFIRA Tour and Travel juga membekali customer service-nya dengan berbagai skill seperti public speaking, product knowledge, dan service excellent sehingga mampu menginformasikan, melayani serta memberikan solusi tepat bagi jamaah.

4. Etika bisnis Islam (Amanah) dalam komunikasi pemasaran diterapkan oleh SHAFIRA Tour and Travel dengan cara senantiasa berusaha untuk selalu menepati apa yang telah dijanjikan kepada jamaah, seperti hotel, fasilitas perlengkapan, dan lain sebagainya.

5. Etika bisnis Islam (Tabligh) dalam komunikasi pemasaran dilakukan oleh SHAFIRA Tour and Travel dengan cara menyampaikan informasi umroh maupun haji secara jelas, luwes, transparan, berulang-ulang, tanpa menjelek-jelekkan atau membandingkan dengan biro perjalanan umroh/haji lainnya. SHAFIRA Tour and Travel juga menjalin hubungan kembali dengan jamaah, terutama ketika jamaah telah kembali ke Indonesia.

\section{Hasil Penelitian}

Bisnis Travel di Indonesia memang banyak khususnya Travel yang menawarkan ibadah ke tanah suci dan memang sedang menjadi peluang bisnis yang menjanjikan, karena peningkatan jumlah permintaan terhadap keberangkatan ke tanah suci di setiap tahunnya. Hal ini karena orang-orang yang berminat untuk mengunjungi tanah suci meningkat pula terlebih lagi jika sedang mendekati hari raya Haji. Berdasarkan penelitian yang telah dilakukan, diperoleh data yang menunjukkan beberapa kondisi terkait aktivitas sarana promosi di SHAFIRA Tour and Travel :

1. SHAFIRA melakukan keenam bauran promosi yang ada walaupun satu diantara enam tersebut masih digolongkan untuk project kedepannya. Enam bauran promosi tersebut antara lain : Iklan, promosi penjualan, publisitas dan Hubungan Masyarakat, Penjualan pribadi, pemasaran langsung, dan Acara dan Pengalaman. Sarana promosi Word of Mouth dilakukan oleh Jamaah yang sudah pernah merasakan dan puas akan pelayanan yang diberikan oleh SHAFIRA Tour and Travel. Dari keenam bauran promosi yang dilakukan oleh SHAFIRA, jamaah hanya mengetahui empat bauran promosi yaitu Iklan, Promosi Penjualan, Penjualan Pribadi, Pemasaran Langsung.

2. $75 \%$ dari jamaah SHAFIRA Tour and Travel mengetahui produk jasanya melalui sarana promosi word of mouth yang dilakukan oleh jamaah yang puas akan pelayanan dan perjalanannya. Hal ini akan membantu SHAFIRA dalam hal menekan budget cost dalam hal promosi tehadap produknya.

3. Enam bauran promosi yang dilakukan SHAFIRA dikemas dengan promosi yang 
Rhodiyah LD, et al/Jurnal Ekonomi Syariah Teori dan Terapan Vol. 3 No. 1 Januari 2016: 1-15; PENERAPAN PROMOTIONAL MIX PADA BIRO PERJALANAN UMROH/ HAJI SHAFIRA TOUR AND TRAVEL SURABAYA MENURUT PERSPEKTIF ISLAM.

sesuai dengan perspektif Islam yaitu Jujur, Amanah, Tidak mempromosikan barang haram, dan juga Nasehat.

\section{SIMPULAN DAN SARAN}

\section{Simpulan}

Berdasarkan analisis dan pembahasan, maka diperoleh simpulan sebagai

berikut:

1. SHAFIRA melakukan keenam bauran promosi yang ada walaupun satu diantara enam tersebut masih digolongkan untuk project kedepannya. Enam bauran promosi tersebut antara lain : Iklan, promosi penjualan, publisitas dan Hubungan Masyarakat, Penjualan pribadi, pemasaran langsung, dan Acara dan Pengalaman. Sarana promosi Word of Mouth dilakukan oleh Jamaah yang sudah pernah merasakan dan puas akan pelayanan yang diberikan oleh SHAFIRA Tour and Travel. Dari keenam bauran promosi yang dilakukan oleh SHAFIRA, jamaah hanya mengetahui empat bauran promosi yaitu Iklan, Promosi Penjualan, Penjualan Pribadi, Pemasaran Langsung.

2. Enam bauran promosi yang dilakukan SHAFIRA dikemas dengan promosi yang sesuai dengan perspektif Islam yaitu Jujur, Amanah, Tidak mempromosikan barang haram, dan juga Nasehat.

\section{Saran}

Saran yang dapat diberikan berdasarkan hasil analisis dalam penelitian ini adalah:
A. Bagi SHAFIRA Tour and Travel

Bagi SHAFIRA Tour and Travel hendaknya menghimbau aktivitas sarana promosi yang telah dilakukan dan agar tetap selalu melaksanakan nilai-nilai yang tidak bertentangan dengan figh muamalah pada setiap aktivitas bisnis travel baik dalam hal operasional, pemasaran, maupun pada bauran promosi yang digunakannya. Alasan yang juga mendasari pernyataan tersebut karena Travel agency merupakan sebuah lembaga bisnis yang sangat diperlukan oleh masyarakat oleh karena itu diharapkan senantiasa menanamkan nilai-nilai Islam sehingga dapat dipercaya oleh masyarakat selain itu, diharapkan juga bagi SHAFIRA untuk memperbanyak promosi terhadap produk-produknya agar masyarakat tahu akan keberadaan sarana-sarana promosi yang dilakukan oleh SHAFIRA karena hampir sebagian besar jamaah mengetahuinya berdasarkan informasi yang diucapkan oleh orang lain.

B. Bagi Penelitian Selanjutnya Penelitian ini masih terdapat banyak kekurangan dan keterbatasan, sehingga bagi penelitian selanjutnya, perlu dilakukan penelitian yang lebih komprehensif dan mendalam tentang pemasaran bisnis Islam. Penelitian dapat dilakukan dengan implementasi nilai-nilai pemasaran terhadap bisnis Islam khususnya di wilayah Surabaya. Pada penelitian ini terdapat beberapa hal yang menarik untuk diteliti lebih lanjut terutama mengenai unsur-unsur Marketing Mix 
Rhodiyah LD, et al/Jurnal Ekonomi Syariah Teori dan Terapan Vol. 3 No. 1 Januari 2016: 1-15; PENERAPAN PROMOTIONAL MIX PADA BIRO PERJALANAN UMROH/ HAJI SHAFIRA TOUR AND TRAVEL SURABAYA MENURUT PERSPEKTIF ISLAM.

menurut perspektif Islam yang terdiri dari 5P yaitu Price, Place, Product, Promotion, and People. Adapun saran penelitian yang dilakukan pada Marketing Mix tersebut adalah penelitian yang bersifat eksploratif guna membahas dan mendefinisikan setiap unsur yang terdapat pada teori tersebut.

\section{DAFTAR PUSTAKA}

Al-Qur'an dan Hadits

Ajeng, Syarifah. Implementasi Nilai Tabligh dalam Bauran Promosi Pada Bank Umum Syariah " $X$ " di Surabpaya. Skripsi ini tidak diterbitkan. Universitas Airlangga

Al-Qarni, 'Aidh.2009. Tafsir Muyassarjilid 1.Jakarta: Qisthi Press

Al-Qarni, 'Aidh.2009. Tafsir Muyassarjilid 3.Jakarta: Qisthi Press

Al-Qur'an dan Terjemahannya. 2012. Jakarta:Dapartemen Agama Republik Indonesia.

Anonim.2015.SHAFIRA Tour and Travel, Perjalanan Haji Memuaskan. http://www.pressreader.com/indonesia ¿jawa-

pos/20151014/281861527339951/TextVie w (Online). Diakses pada tanggal 31 Oktober 2015 pukul 12:00

Anwar, Mohammad dan Mohammad Saeed.1996.Promotional Tools of Marketing: An Islamic Perspective. Intelectual Discourse Vol 4 no 12.http://journals.iium.edu.my/intdiscours e/index.php/islam/article/download/38
7/334. Diakses pada tanggal 29 Oktober 2015 pukul 20:00

Basrowi, dan Suwandi.2008.Memahami Penelitian Kualitatif.Jakarta: Rineka Cipta

Basu, Swastha DH.1999.Saluran Pemasaran.BPFE. Yogyakarta

Berten, Kees.2000. Pengantar Etika Bisnis. Yogyakarta: Kanisius

Esso, Nittin dan Sally Dibb. 2004. Religious Influences on Shopping Behaviour: An Explanatory Study. Journal Of Marketing Management. 20 (7-8) 683712

Fandy Tjiptono. 1997. Strategi Pemasaran, Edisi 1. Penerbit Andi. Yogyakarta.

Ghazaly, Abdul Rahman dkk. 2010. Fikih Muamalah. Jakarta: Kencana Prenada Media Grup.

Gunara, Torik. dan Utus Hardiono Sudibyo. 2008. Marketing Muhammad. Bandung: Madania Prima

Haekal, Muhammad Husain.2005.Sejarah Hidup Muhammad.Jakarta: PT Mitra Kerjaya Indonesia.

Haroen, Nasrun, 2007, Fiqh Muamalah, Jakarta: Gaya Media Pratama

Hartono.201 1.Metode

Penelitian.Pekanbaru: Zanafa Publishing Hassan, Abul, dkk. 2008 . Islamic Marketing Ethics and Its Impact on Customer Satisfaction in the Islamic Banking Industry. JKAU : Islamic Economics 21 (1). Diakses pada 17 Maret 2015 di http://www.kau.edu.sa/Files/320/Resear ches/46660_18233.pdf

Hosseini, Mirza Hasan dan Mohsen Safaie navaie. 2012. Analyzing The Influence 
Rhodiyah LD, et al/Jurnal Ekonomi Syariah Teori dan Terapan Vol. 3 No. 1 Januari 2016: 1-15; PENERAPAN PROMOTIONAL MIX PADA BIRO PERJALANAN UMROH/ HAJI SHAFIRA TOUR AND TRAVEL SURABAYA MENURUT PERSPEKTIF ISLAM.

Of Promotion Mix On Increase Of Sale In Cosmetics And Beauty Products. http://www.ajbms.org/issue.php?id=4.

Asian Journal of Business and Management Sciences. 30 Oktober 2015

Ibn Taymiyah (1982) Public Duties in Islam:

The Institution of the Hisbah, translated

by Muhtar Holland, The Islamic Foundation, Leicestershire.

Ibn al-Ukhuwwah, Diya' al-Din

Muhammad (1983) Ma'alim al-Qurbah

fi Ahkam al-Hisbah, Translated by

Reuben Levy, Luzak, London.

Irawan,dkk.1997,. Pemasaran: Prinsip dan

Kasus, Edisi Kedua hal. 163-164. GBPFE,

Yogyakarta, Indonesia.

Kamdhi

JS.2003.Terampil

Berargumentasi.Jakarta:PT Grasindo

Karim, Adhiwarman.2014. Bank Islam : Analisis Fiqih dan Keuangan Edisi Kelima. PT. Raja Grafindo.Jakarta

Kartajaya, Hermawan dan Muhammad Syakir Sula.2006.Syariah Marketing. Mizan Pustaka.Bandung

Kasmir, dan Jakfar.2004. Studi Kelayakan

Bisnis, cet II. Kencana. Jakarta

Kementrian Agama Republik

Indonesia.2015. Laporan

Penyelenggaraan Umroh tahun 2015.

http://kantorurusanhaji.com/laporan-

kedatangan-dan-kepulangan-ppiu/.

Diakses pada tanggal 25 Mei 2015 pukul 22:00

Khairiyah, Nadiatul.2011. Evaluasi

Pelayanan Umroh Angkatan Ke-6 Tahun

2011 PT MULIA TOUR JAKARTA. Skripsi ini tidak diterbitkan. Universitas Islam Negeri

Kotler, Philip.2000. Marketing Management

"Product Differentiation".New

Jersey: Prentice Hall International, Inc. .2005.Manajamen

Pemasaran, Jilid 1 dan 2. Jakarta: PT. Indeks

Kelompok Gramedia. .2006.Manajemen

Pemasaran.Edisi Kesebelas. Jilid 1. Terjemahan Oleh Benyamin Moan. 2006. Jakarta: indeks .2009 . Manajemen

Pemasaran 1, Edisi ke-13. Jakarta: PT.Erlangga

Kotler, Philip dan Kevin Lane Keller., 2007, Manajemen Pemasaran, Edisi Kedua Belas, Jilid 1, dialihbahasakan oleh Benjamin Molan, Jakarta: PT Indeks.

2007. Manajemen

Pemasaran, Edisi Kedua Belas, Jilid 2, dialihbahasakan oleh Benjamin Molan, Jakarta: PT Indeks.

Kum-Lung, Choe and Teck-Chai, Lau. 2010. Attitude towards Business Ethics: Examining the influence of Religiosity, Gender and Education Levels. International Journal of Marketing Studies 2 (1).

Miles, Matthew B. and A. Michael Huberman. An Expanded Source Book: Qualitative Data Analysis .London: Sage Publications.

Moleong, LJ. 1989. Metodologi Penelitian Kualitatif. Remaja Rosdakarya. Bandung. 
Rhodiyah LD, et al/Jurnal Ekonomi Syariah Teori dan Terapan Vol. 3 No. 1 Januari 2016: 1-15; PENERAPAN PROMOTIONAL MIX PADA BIRO PERJALANAN UMROH/ HAJI SHAFIRA TOUR AND TRAVEL SURABAYA MENURUT PERSPEKTIF ISLAM.

Muflih, Muhammad.2006. Perilaku Konsumen dalam Perspektif IImu Ekonomi Islam. Jakarta:PT Raja Grafndo Persada

Nizam, Ahmad dan Alatif Hasan.2000. Manajemen Haji. Jakarta:Zikru Hakim

Pratiwi, Intan Kusuma.2013.Penerapan Etika Bisnis Islam dalam Komunikasi Pemasaran Biro Perjalanan Umroh/Haji 'SHAFIRA Tour and Travel' Surabaya. Skripsi ini tidak diterbitkan. Universitas Airlangga

Qardhawi, Yusuf. 1997 . Peran Nilai dan Moral dalam Perekonomian Islam. Jakarta: Robbani Press

Rambat Lupiyoadi. (2001). Manajemen Pemasaran Jasa (Teori dan Praktek). Edisi Pertama. Penerbit Salemba Empat,Depok.

Rapar, Jan Hendrik.1996.Pengantar Logika, Asas-Asas

Penalaran.Yogyakarta: Kanisius

Richard J. Semenik. 2002. Promotion and Integrated Marketing Communication. Ohio. South Western Thompson learning Rizal, Saiful. 2015. Cermat Memilih Biro Perjalanan Umroh Dan Haji.http://sinarharapan.co/news/read/ 150527098/cermat-memilih-biroperjalanan-umroh-dan-haji. Diakses pada 29-Mei-2015 pukul 21:00

Sandy, dkk.2014.Pengaruh Bauran Promosi Terhadap Keputusan Pembelian (Survei pada Mahasiswa Jurusan Bisnis Angkatan 2010-2012) Fakultas IImu Administrasi Pengguna Indosat di Universitas Brawijaya).Universitas $\begin{array}{llll}\text { Brawijaya. } & \text { Vol } & 9 & \text { No.2. }\end{array}$ http://administrasibisnis.studentjournal.u b.ac.id/index.php/jab/article/view/412. 30 Oktober 2015

Shaw, M. 1996. "Civil Society and Media in Global Crises", St. Martin Press, London.

Sitorus, MTF. 1998. Penelitian Kualitatif: Suatu Perkenalan. Dokis. Bogor.

Sugiyono. 1999. Metode Peneitian Bisnis. Bandung :Alfabeta

Sunday A. , Adebisi and Babatunde Bayode O.2011.Strategic Influence Of Promotional Mix On Organization Sale Turnover In The Face Of Strong Competitors.http://www.saycocorporati vo.com/saycoUK/BIJ/journal/Vol4No2/A rticle_13.pdf. SaycoUK.30 Oktober 2015

Suprayogo, Imam.2008. Ibadah Haji dan Tradisi Berziarah.http://old.uinmalang.ac.id/index.php?option=com content \&view $=$ article \&id $=487 \% 3 \mathrm{~A} 15-12$ 2008\& catid $=25 \% 3$ Aartikel-imamsuprayogo\&ltemid=173 (Online). Diakses pada 31 Oktober 2015 pukul 10.00

Tim Redaksi. 2014. The Wisdom Al-Qur'an Al-Karim.Bandung.PT Mizan Bunaya Kreativa

Yin, Robert K. 2012 . Studi Kasus Desain \& Metode. Jakarta. PT. Raja Grafindo 